\title{
Determination the Flow Net through Multi Layers Soil by Using the Hydraulic Modeling Method
}

\author{
Hala Kathem Taeh Alnealy \\ Civil Engineering Department, Babylon University, Iraq
}

Email address:

halhhalh300@yahoo.com

To cite this article:

Hala Kathem Taeh Alnealy. Determination the Flow Net through Multi Layers Soil by Using the Hydraulic Modeling Method. American Journal of Civil Engineering. Vol. 3, No. 3, 2015, pp. 80-87. doi: 10.11648/j.ajce.20150303.15

\begin{abstract}
In this research the experimental method by using Hydraulic modelingused todetermination the flow net in order to analyses seepage flow through multi- layer soil foundation underneath hydraulic structure.as well as steady theconsequence ofthe cut-off inclination angle on exit gradient, factor of safety, uplift pressure and quantity of seepage by using seepage tank were designed in the laboratory with proper dimensions with two cutoffs. The physical model (seepage tank) was designed in two downstream cutoff angles, which are $\left(90\right.$, and $\left.120^{\circ}\right)$ and upstream cutoff angles $\left(90,45,120^{\circ}\right)$. After steady state flow the flow line is constructed by dye injection in the soil from the upstream side in front view of the seepage tank, and the equipotential line can be constructed by piezometer fixed to measure the total head. From the result It is concluded that using downstream cut-off inclined towards the downstream side with $\Theta$ equal $90^{\circ}$ that given value of redaction $(25 \%)$ is beneficial in increasing the safety factor against the piping phenomenon.using upstream cut-off inclined towards the downstream side with $\Theta$ equal $90^{\circ}$ that given value of redaction $(31 \%)$ is beneficial in decreasing uplift pressure and quantity of seepage.
\end{abstract}

Keywords: Flow Net, Inclined Cut-Off, Hydraulic Structures

\section{Introduction}

Hydraulic structures like barrages, dams, regulators, weirs, sheet pile wall.etc, area specific type of engineeringstructures designed and executed in such a way in order to operate them to control natural water or save industrial sources to guarantee optimumuse of water. These structures are frequently build on soil materials and the foundation thickness must be thick so as to be safe against uplift pressure (AL-Ganaini 1984). The analysis and design of foundation, as compared with other parts of the structure, should be given greatest importance because failure in the foundation would destroy the whole structure.the differential head in water levels between theupstream and downstream acts on the foundation and causes seepage flow (Selim 1947) Different methods solution can be used to analysis the seepage problem such as experimental works using physical model as well as numerical models (EL-Fitiany et al 2003). A flow net is in fact a solution of Laplace's equation in two dimensions. The model of seepage tank (sand tank)is very useful in studying the conditions of fluid flow under the hydraulic structure (Roy 2010). The hydraulic modeling method to determine the flow net in this study represented by a physical model was built to study the phenomenon of seepage through soil using different types of soil under the hydraulic structure foundation (multi layers soil). And the factor of safeties will be found for each position.

\section{Literature Review}

Various theories and investigations were put forward to predict seepage phenomenon and determination flownet by experimental and numerical methods.Abourohim (1992) investigate the effect of seepage underneath the structures that generated uplift pressure acting on structures with: i) simple floor and ii) floor having an intermediate sheet pile by using a sand model. He concluded that such an effect becomes negligible when the canal width exceeds 2.6 times the length of the floor of the structure. Desai and Christian, (1977): studied the seepage through a two layered foundation of a dam, within each layer the soil was assumed homogenous,they used the finite element method. The computed values from the finite element method were compared with those from graphical solutions. Zheng-yi. and Jonathan, (2006): used the finite elementmethod to analyze seepage through a two-layer soil system. The program SEEP was employed to analyze flow characteristics of an 
impervious dam with sheet pile on a layered soil. The results were reduced to simple charts, The chart curves allow a designer to obtain solutions to the seepage problem. and can be extended to a soil system comprising more than two layers.Arslan and Mohammad, (2011)measured the pizometric head distribution under hydraulic structures and studied the effect of upstream, intermediate and downstream sheet piles inclination. using experimental method. The study consisted 12 separated case of these inclined sheet piles with changing the direction of this inclination. they foundthe optimum case of the uplift pressure reduction.

\section{Objectives of the Study}

The main objectives of this work can be summarized by the following points:

1. Equipotential lines and flow lines were located by conducting experiments on a known sample in a seepage tank and for multi-layers soil used in research work.

2. Study the effect of inclined cutoffs at different angles of inclination on exit gradient, uplift pressure underneath the hydraulic structure quantity of seepage and find the best inclination angle of cut-off for upstream and downstream side of hydraulic structure for all types of soils placed in different position under the foundation of hydraulic structure used in research work.

\section{Experimental Work}

The results obtained by the present hydraulic model using the seepage tank that designed and carried out at the hydraulic laboratory of the Engineering College at Babylon University. The major purpose of the physical model adopted in the present research is to study the flow net and calculate the values of uplift pressure underneath the hydraulic structure, distribution of exit gradient, quantity of seepage for different types of soil at different position under the hydraulic structure foundation.

\section{Engineering Properties of Soil Used in Research}

The experimental soil sample was taken from Hilla city region. The soil profile of any region contains many soil horizons, the difference between these horizons is marginal (no-homogenous soil). In the model tests, the profile is assumed to consist of one horizon (homogenous soil) (Aziz 2008). The tests used here to analyze the soil specimen in order to determine soil distribution and other engineering properties were conducted as per the Unified Soil Classification System, also the hydraulic conductivity values of the soil samples was measured inlaboratory method.Table 1 shows a summary of the physical properties that measured of the soils which consist of three layers arranged in descending order.used in the present study.figure (1) shown the arrangedfor type of soil used in present study.

Table 1. Physical properties of used soils.

\begin{tabular}{llllll}
\hline \multirow{2}{*}{ No of layer. } & Type off soil Arrange in descending order & Void ratio & Unit weightKN/m3 & Gs & $\begin{array}{l}\text { Value of Hydraulic Conductivity } \\
\text { m/sec }\end{array}$ \\
\hline 1 & Well-graded clayey Sandy silt & 0.77 & 19.5 & 2.66 & $8.32 * 10-5$ \\
2 & Poorly-graded sand & 1.35 & 16.73 & 2.63 & $9.453 * 10-4$ \\
3 & Sandy silt & 0.58 & 20.2 & 2.68 & $4.899 * 10-4$ \\
\hline
\end{tabular}

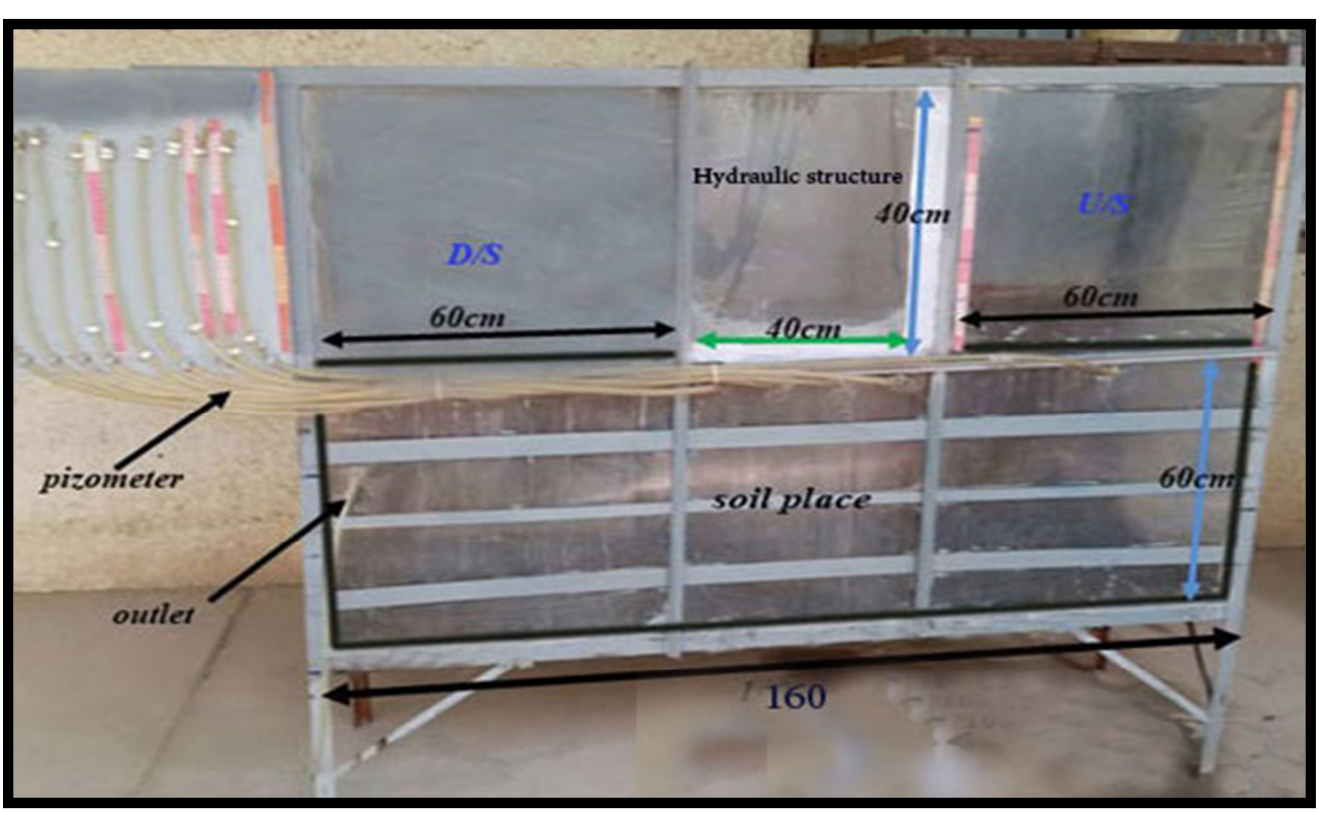

Figure (1). the seepage tank used in present study (front view). 
Laboratory experiments have been conducted in a seepage tank that has been designed with hypnotically dimensions of $1.6 \mathrm{~m}$ long, $0.5 \mathrm{~m}$ width and $1.1 \mathrm{~m}$ height The bottom and sidewalls of this tank were made of Acrylic of $(10 \mathrm{~mm})$ thickness. Figure (1)shows the seepage tank used in present study (front view). The bottom of the tank was filled with this material of soil to a depth of $60 \mathrm{~cm}$. Acrylic walls were used to build the body of the superstructure which consists of two parts. The first part simulated as foundation of a structure (40 $\mathrm{cm}$ long $\times 50 \mathrm{~cm}$ wide).This base is connected with the upstream and downstream cutoffs by gluing rubber strips. 10 piezometers were placed at the right side of the tank at different location. All piezometers are fixing to the board.

\section{The Experimental Procedures}

1. Taking the datum to be at the bottom of the tank, Install the soil in the form of three layers each layer thickness of $0.2 \mathrm{~m}$ and it is monitoring the process of using. the metal cylinder

2. Feeding the water to the seepage tank through the inlet hose until the water level in the upstream region reached the overflow hose level previously adjusted to meet the desired upstream water level.

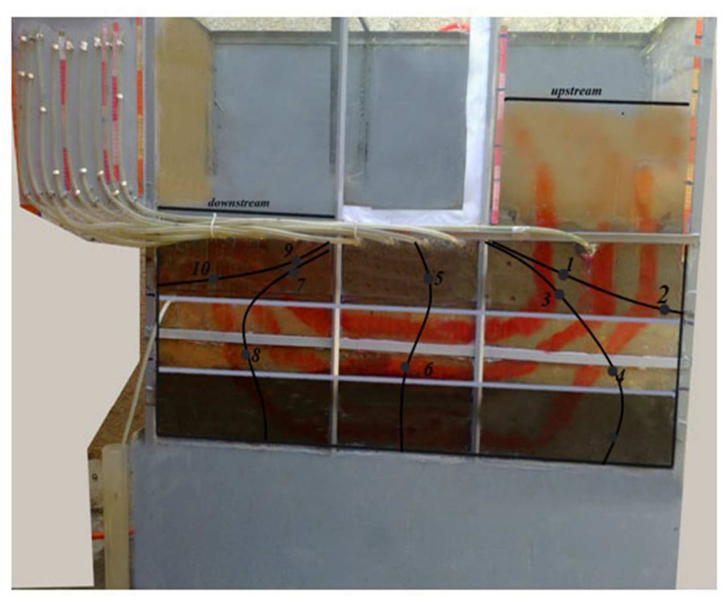

general case (without any cutoff)

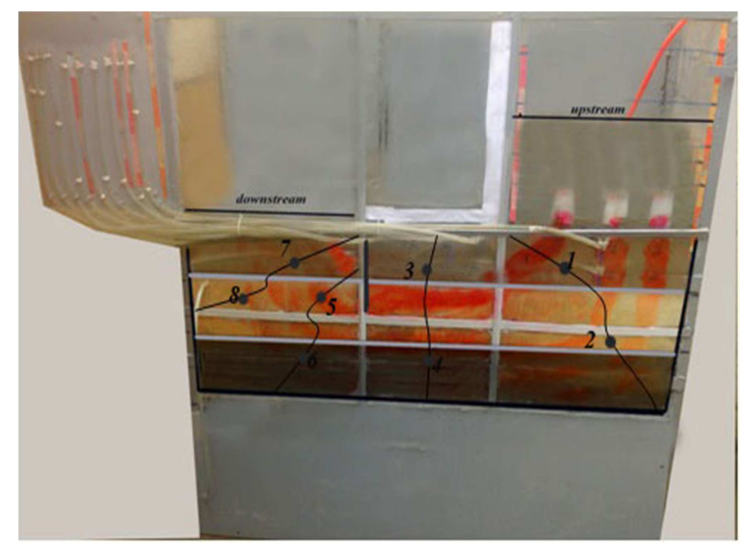

(cutoff at the downstream side $\Theta=90$ )
3. After reachingsteady-state flow dye is injected from dye bottles which placed in the specific points, after a period of time flow lines were drawn Flux, which represents how the flow of water within the soil particles

4. After drawing flow lines, the vertical piezometers were installed transparent glass vertically into the soil to measure the total head in the points to draw the equipotential line.

5. Measure the discharge of drained water collected from the downstream funnel using the volumetric method by using jar.

6. Record the reading of the piezometric head of all installed piezometers under the base and downstream side.

7. Put the cutoffat upstream side with the angle of inclination for upstream $(\Theta=45, \Theta=120, \Theta=90)$ and repeat the step (7-8-9)to find the best angleto gave less value of uplift pressure and quantity of seepage.

8. Put the cutoffat downstream side with the angle of inclination $(\Theta=90, \Theta=120)$ and repeat the step (7-8-9) to find the best angle to give max value factor of safety.

9. figure (2) shown the type of testing that made on multi layer soil

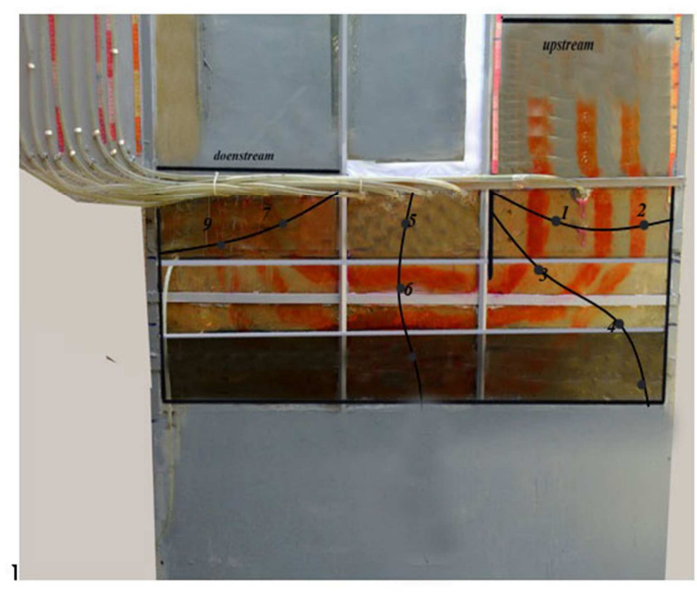

cutoff at the upstream side $\Theta=90$

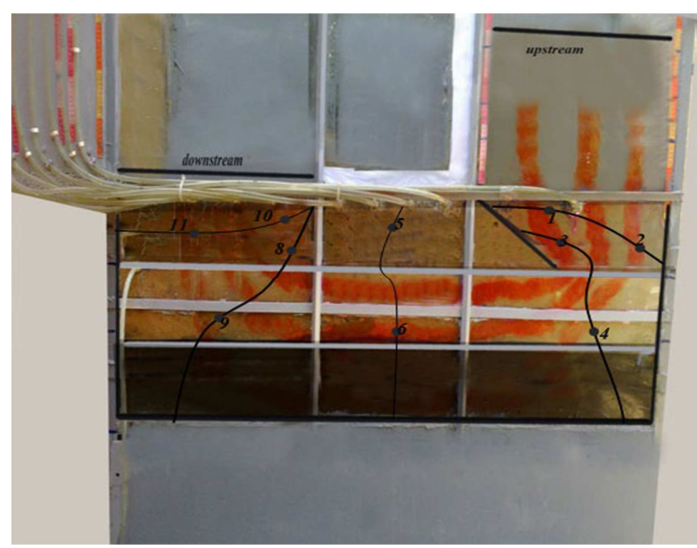

(cutoff at the upstream side $\Theta=45$ ) 


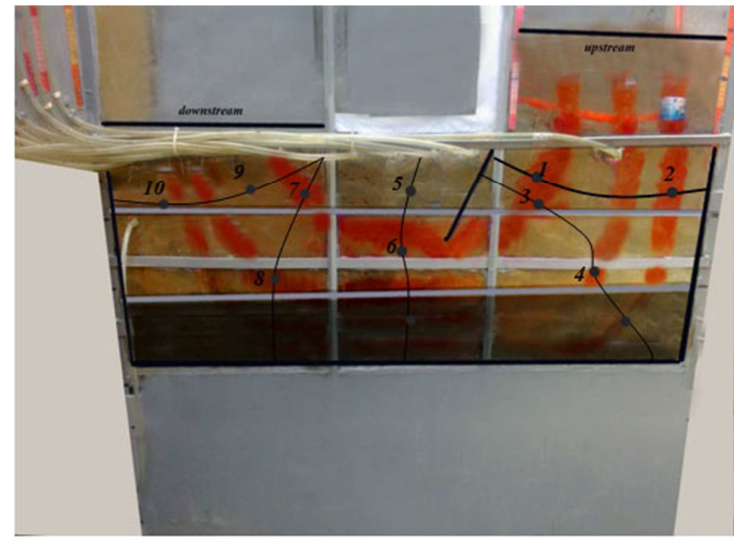

(cutoff at the upstream side $\Theta=120$ )

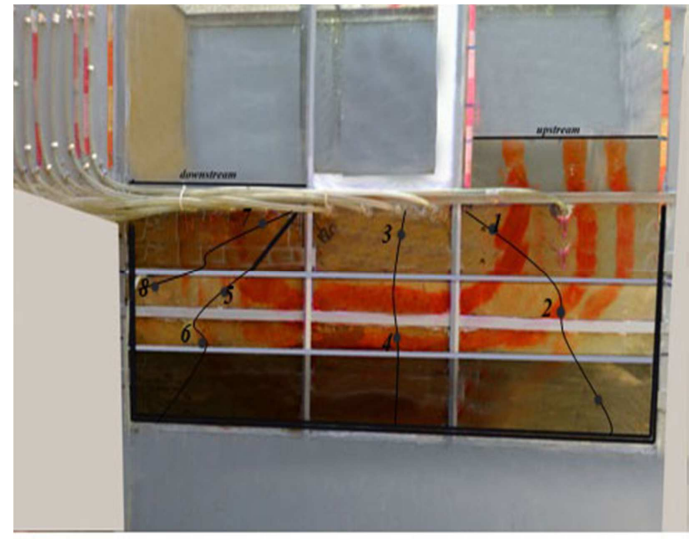

(cutoff at the downstream side $\Theta=120$ )

Figure (2). The model images for third experiment included hydraulic structure resting onmulti-layer soils.

\section{Discussion of Results}

Herein, the discussions of the results for multi layers soils according the following parameters:

\subsection{Effect of Inclined Cutoff and its Position on the Uplift Head}

As shown in figure (3). Whenthe Cutoff in upstream side of hydraulic structure was inclination with different angles, its noticed that the uplift pressure underneath the hydraulic structure decreases as $(\Theta)$ decreases towardU/S side for $\Theta\left(45^{\circ}, 90^{\circ}, 120^{\circ}\right)$ where the maximumredaction in uplift pressure according to the general case $\Theta=0$ (without any cutoff)was(-30\%, $-36 \%,-23 \%)$ respectively ,so that the best angle is $\left(45^{\circ}\right)$.

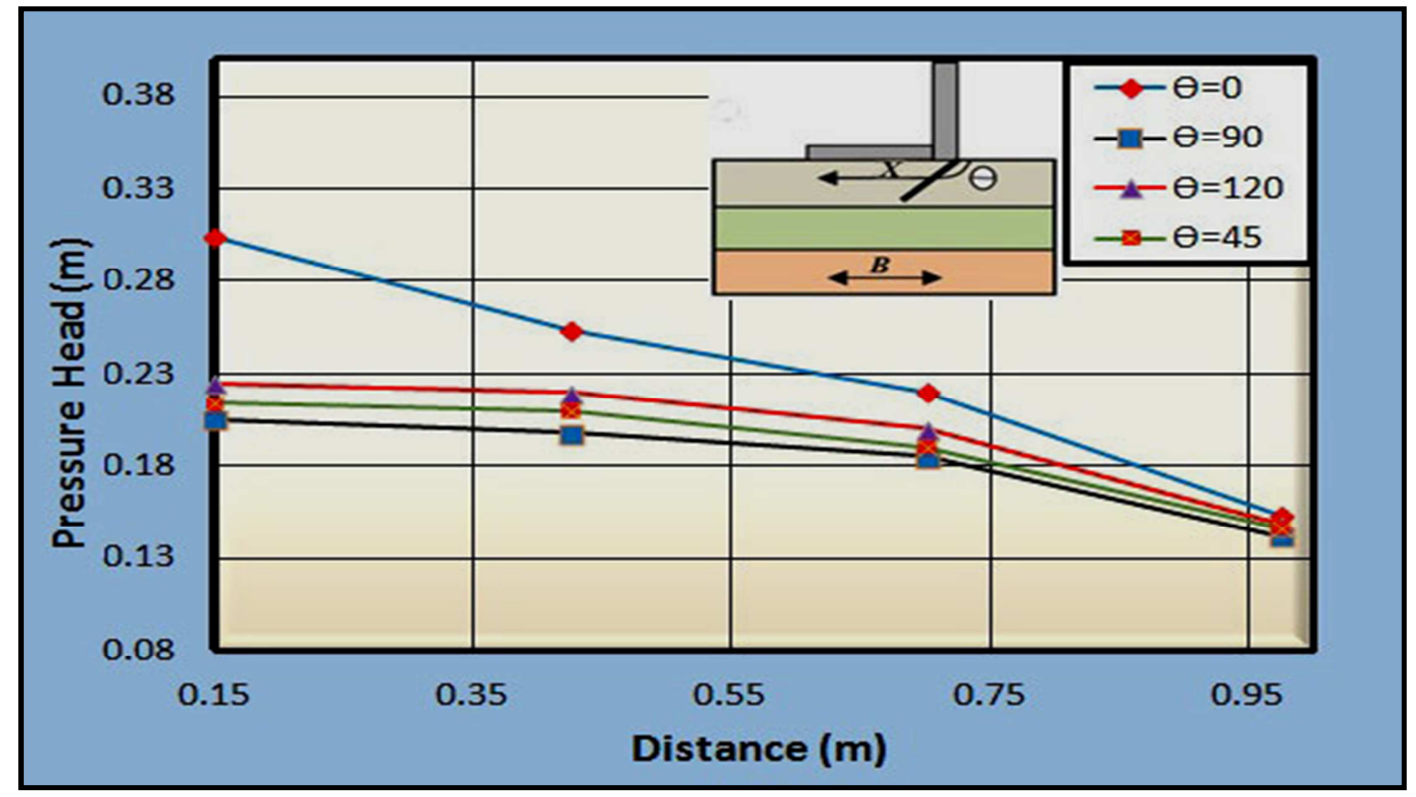

Figure (3). Uplift headfor different values of $(\Theta)$ values for cutoff in $U / S$.

From figure (4). When the Cutoff in downstream side of hydraulic structure is used, the uplift pressure obtained decreases as $(\Theta)$ decreases towardU/S side for $\Theta\left(90^{\circ}\right.$ and $120^{\circ}$ ) and the maximum redaction in uplift pressure according to the general case $\Theta=0$ was $(6 \%$ and $5.4 \%)$. It is noticed that the redaction of the uplift pressure is small to the replacing ofthe cut-off, therefore, it is not recommended under any angle of inclination.

As cutoff positioned in U/S and D/S part of dam structure as shown figure(5), the uplift reduced strongly with maximum difference in value of uplift pressure was $43 \%$. 


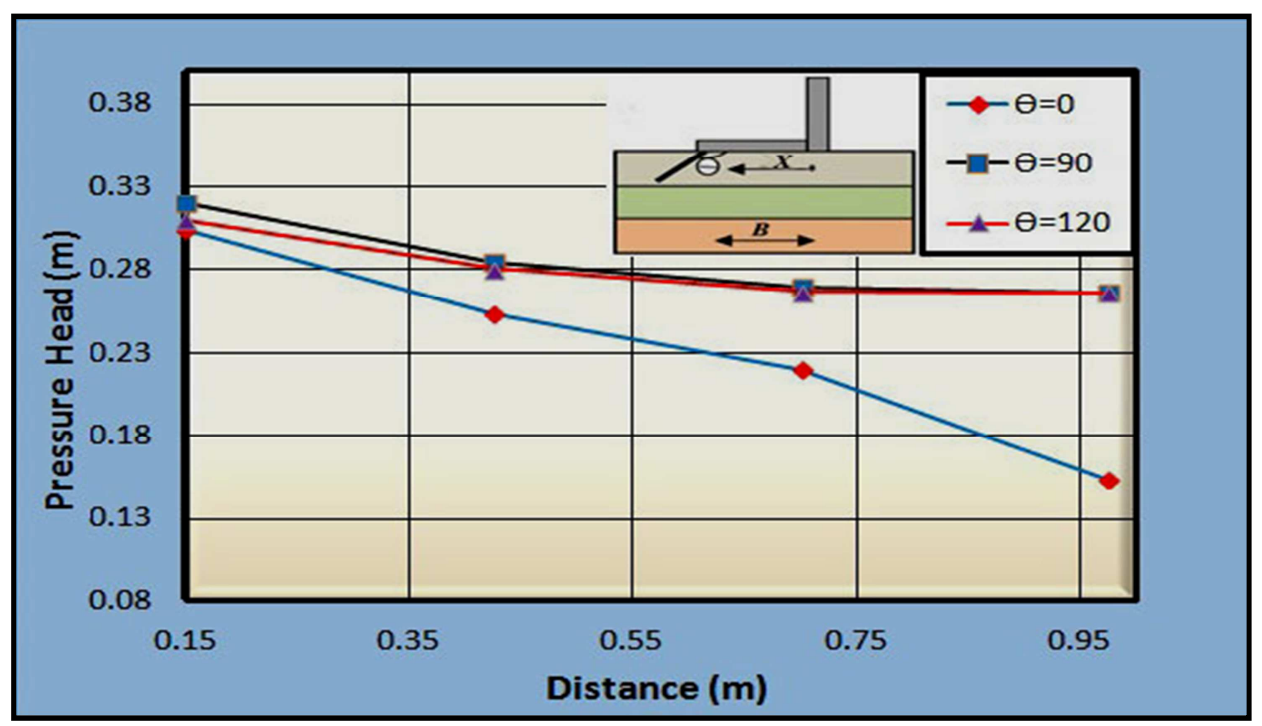

Figure (4). Uplift head for different values of $(\theta)$ values for cutoff in $D / S$.

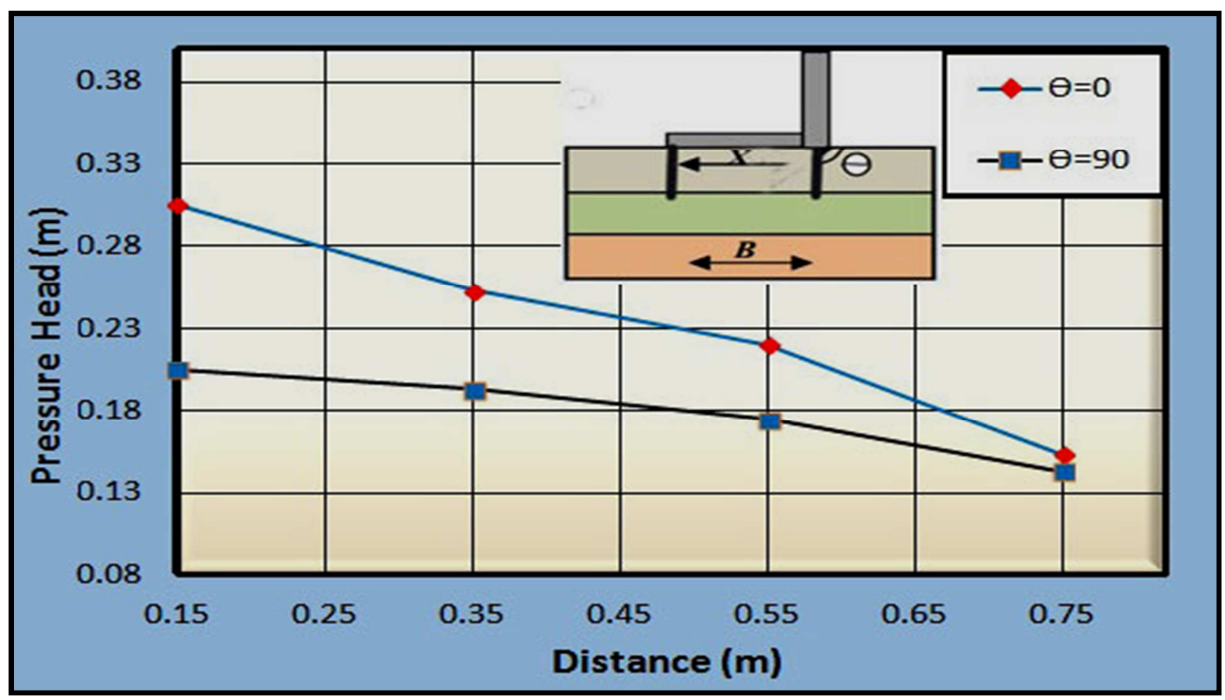

Figure (5). Uplift head for different values of $(\theta)$ values for cutoff in $U / S$ and $D / S$.

\subsection{Effect of Inclined Cutoff and its Position on the Exit Gradient}

The exit gradient was studied at the end of the hydraulic structure for the cases that will be discussed herein and the results are represented graphically. The factor of safety for each angle of inclination must be calculated where is equal to the division of exit gradient on critical gradient (Icr) which is dependent on the specific gravity (Gs) and void ratio (e) of the soil particles $[\mathrm{Icr}=(\mathrm{Gs}-1) /(1+\mathrm{e})]$. In this study andfor this type ofsoil(Gs $=2.75, \mathrm{e}=0.77$, Icr $=0.988$ ).

In figure(6) whenthe cutoff put in upstream side of hydraulic structure it is found that the redaction in values of exit gradient were so small and as follows for $\Theta\left(45^{\circ}, 90^{\circ}, 120^{\circ}\right)$ where the maximumredaction inaccording to the general case $\Theta=0$ (without any cutoff) $(-9 \%,-9.3 \%,-2.1 \%)$ respectively.

The result shows that the upstream cut-off inclination angle has no noticed effect on exit gradient. From the result the factor of safety against piping for this case were shown in table (2).
Table 2. The factor of safety against piping when cutoff atU/S.

\begin{tabular}{l|ll}
\hline U/S Cut-off Inclination & $\max$ (exist gradient) & Fs \\
\hline $0^{\circ}$ & 0.4 & 2.47 \\
$45^{\circ}$ & 0.382 & 2.586 \\
$90^{\circ}$ & 0.375 & 2.63 \\
$120^{\circ}$ & 0.362 & 2.729 \\
\hline
\end{tabular}

In figure(7) whenthe cutoff is put it in downstream side for $\Theta\left(90^{\circ}\right.$ and $\left.120^{\circ}\right)$ the maximum redaction in exist gradientaccording to the general case $\Theta=0$ was $(13.87 \%$, $9 \%$ ), respectively . So that the factor ofsafetyagainst piping phenomenonof this case can becalculated as shown in table (3).These results show thatusing cutoff in $\mathrm{D} / \mathrm{S}$ sideinclination toward $\mathrm{D} / \mathrm{S}$ for $(\Theta=120)$ increasing thefactor of safety against piping. 
Table 3. The factor of safety against piping when cutoff atD/S

\begin{tabular}{lll}
\hline U/S Cut-off Inclination & $\max$ (exist gradient) & Fs \\
\hline $0^{\circ}$ & 0.4 & 2.47 \\
$90^{\circ}$ & 0.35 & 2.82 \\
$120^{\circ}$ & 0.31 & 3.18 \\
\hline
\end{tabular}

That exit gradientwhen the cutoff in the U/S andD/S part of dam structure decreases compare with general case as shown in figure (8) were maximum differencein value of exist gradient was $7 \%$.

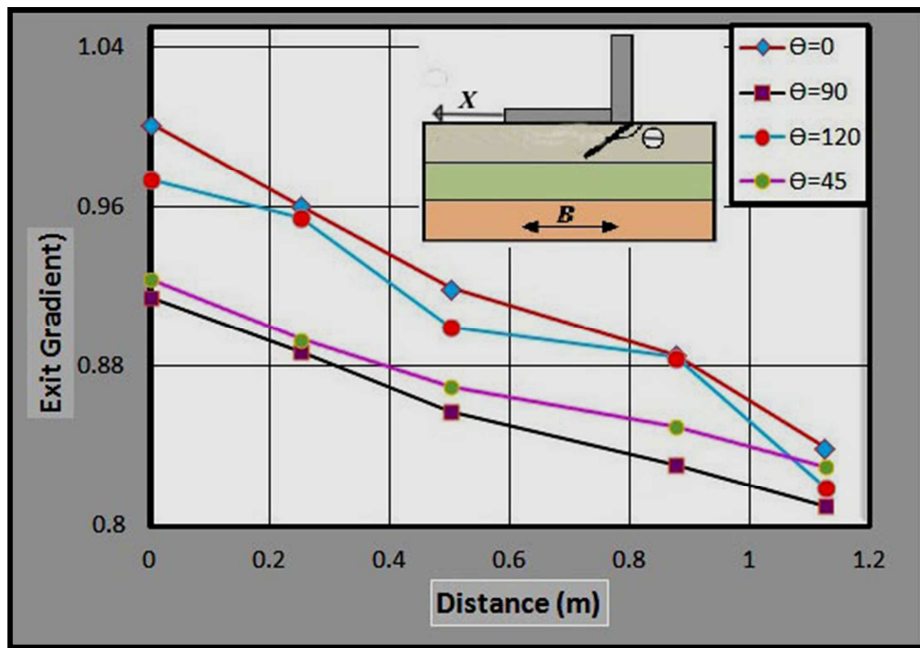

Figure (6). Exit gradient values for different $(\theta)$ values for cutoff in $U / S$.

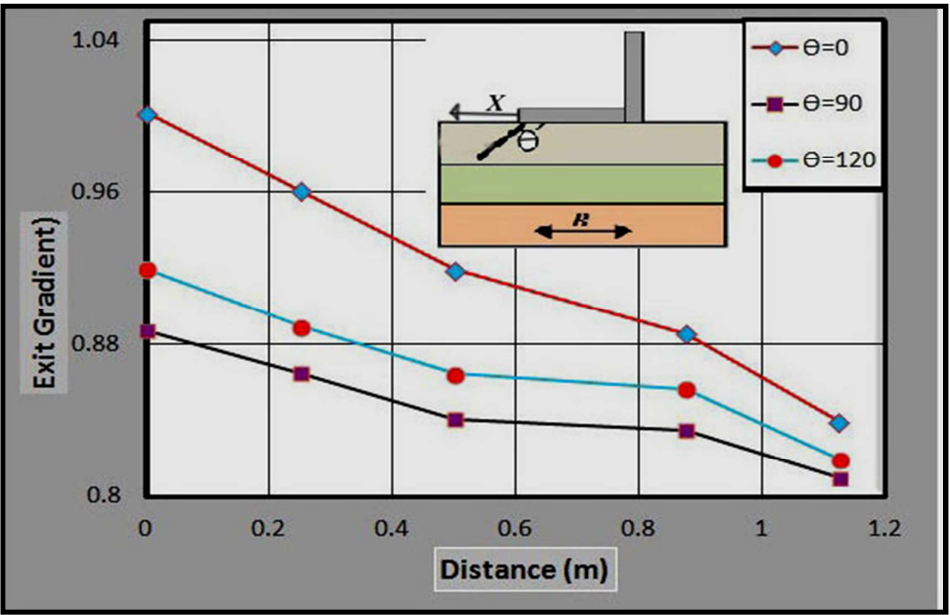

Figure (7). The exit gradienta range of $(\theta)$ values forcutoff in $D / S$.

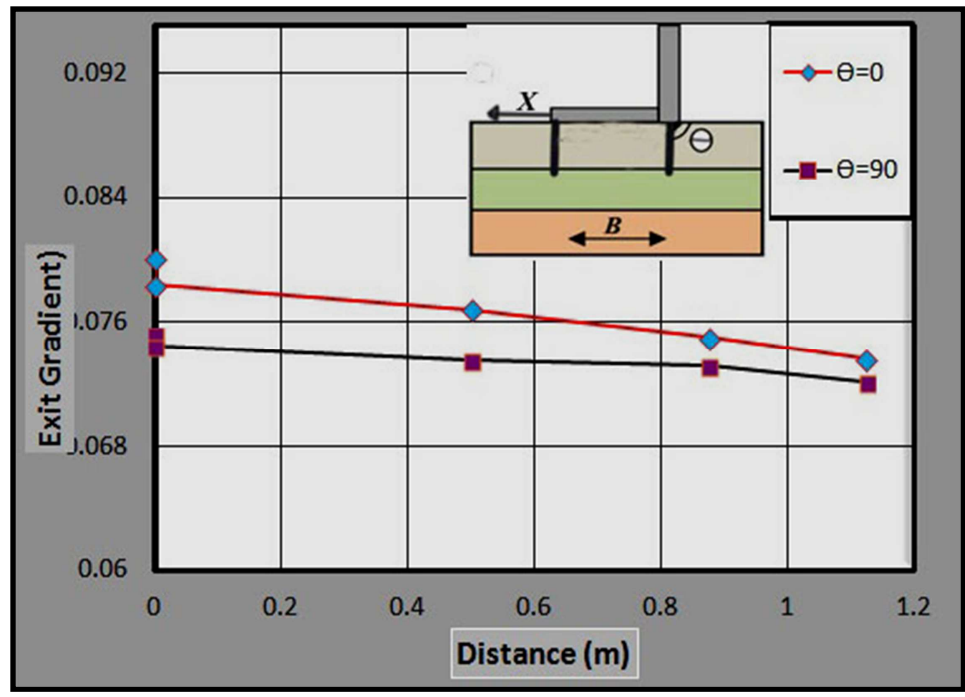

Figure (8). The Exit gradienta range of $(\Theta)$ values for cutoff in $U / S$ and $D / S$. 


\subsection{Effect of Cutoff Position and Inclination on the Seepage Quantity}

When theCutoff is in upstream side of hydraulic structure,as shown in figure(9), it's found that the seepage decreases while $(\Theta)$ decrease towardU/S, and the least quantity of seepage occurred when $(\Theta)$ value around $(90)$.

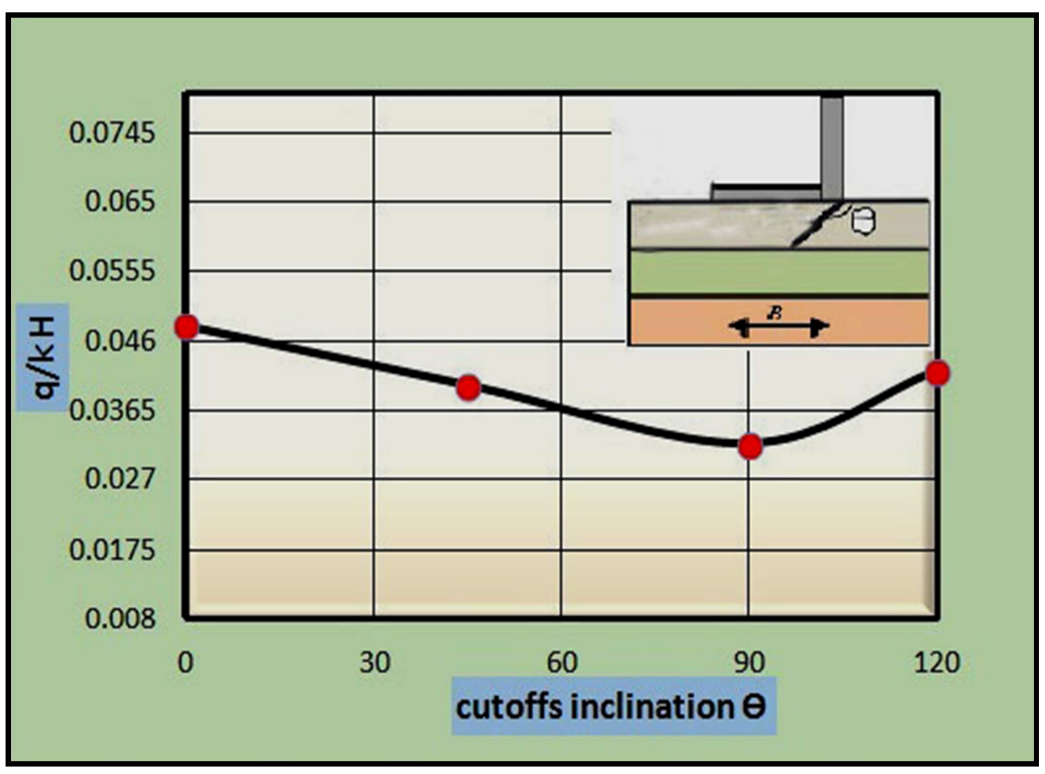

Figure (9). The Seepage quantitya range of different values $(\Theta)$ for cutoff inU/S part of structure.

In figure(10) Whenthe Cutoff is in upstream side of hydraulic structure the seepage decreases while $(\Theta)$ increases, and the least quantity of seepage occurred when $(\Theta)$ value around $(120)$, then the seepage increases rapidly for $(\Theta \leq 90)$.

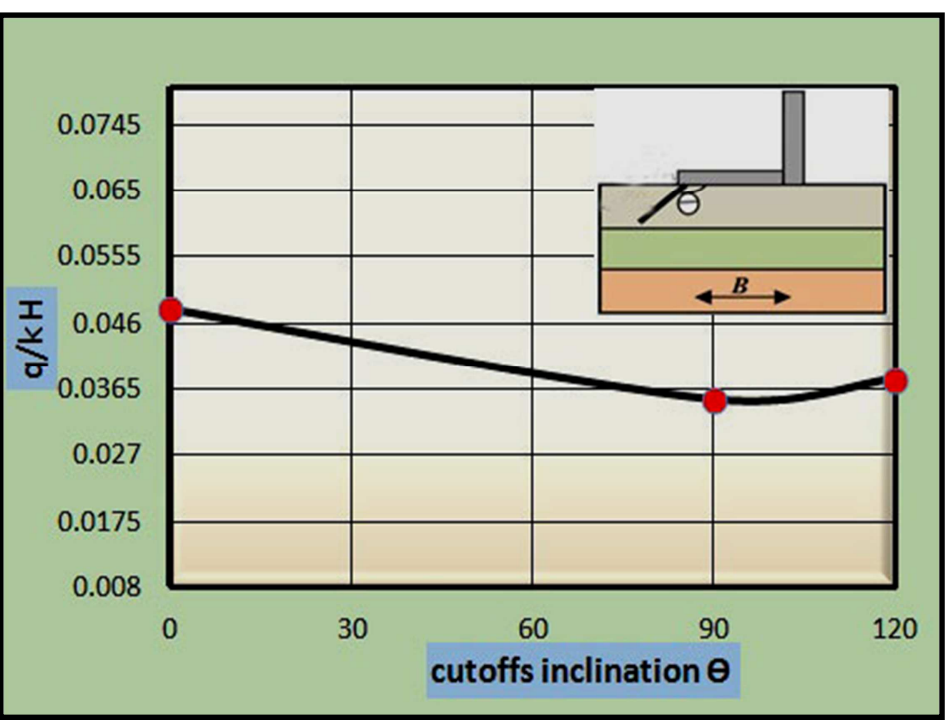

Figure (10). The Seepage quantitya range of different values (O)for cutoff in D/S part of structure.

\section{Conclusions}

The following main conclusions can be drawn from the results presented in this research:

1. The shapes of the flow net depend upon many factors such as diameter of the particle of the soil and location of cutoff.

2. The shape of the flow net obtained by experimental work (seepage tank model) and the result by slide model shows a good agreement.
3. The minimum value of uplift pressure is obtained when the cutoff used in upstream part of hydraulic structure is at the right angle of inclination $\left(\Theta=90^{\circ}\right)$.

4. The exit gradient in downstreamside and amount of seepage decreased to minimum when putting the cutoff at right angle of inclination for both up or downstream part cutoff.

5. Placing an inclined cut-off at the hydraulic structure heel and toe is not recommended under any angle of inclination. 
6. Using double cutoff at the up and downstream part of dam at the right angle is useful to reduce the uplift pressure, exist gradient, and quantity of seepage at the same time.

\section{References}

[1] Abourohim, M. A., (1992) "Experimental study for the effect of seepage past Hydraulic Structures on the uplift pressure along the floo", Alexandria Engineering Journal, Volume 31, Issue 1.

[2] AL-Ganaini, M.A., (1984), "Hydraulic Structure”, Beirut,pp47-60, (In Arabic).

[3] Selim, M.A., (1947) "Dams on Porous Media", Transaction ASCE, Vol. 1 Roy, S.K.(2010). "Experimental Study On Different Types Of Seepage Flow Under The Sheet Pile Through Indigenous Model.", M.Sc. Thesis Insoil Mechanics and Foundation Engineering, University Of Jadavpur.12, pp 488-526.

[4] Desai S.C. and Christian T.J. (1977). "Numerical methods in geotechnical engineering."McGraw-Hill Book Company, New York.
[5] Zheng-yi F. and Jonathan T.H.(2006). "The epsilon method: analysis of seepage beneath an impervious dam with sheet pile on a layered soil."NRC Research Press, Canada Geotechnical Journal Volume 43, P59-69.

[6] Aziz, L. J. (2008). "Lateral Resistance of Single Pile Embedded in Sand with Cavities."D.Ph Thesis, University of Technology, Iraq.

[7] EL-Fitiany, M. A. Abourohim, R. I. and El-Dakak, A. Y. (2003). "Three dimensional ground water seepage around a simplehydraulic structure." Alexandria Engineering Journal, Volume 42 ,Issue 5, September.

[8] Arslan, C. A. and Mohammad, S. A. (2011)."Experimental and Theoretical Study for Pizometric Head Distribution under Hydraulic Structures." Department of Civil engineering; College of engineering, University of kirkuk Volume 6, No.

[9] AL-Kubaisy,Y.K.Y.,(2004), " Effect of Soil Nonlinearity and Construction Sequence on the Behavior of Sheet Pile Wall", Department of Building and Construction Eng.,University of Technology ,Iraq.

[10] Das, B. M. (2008)."Advanced Soil Mechanics." Third Edition. Taylor and Francis, 270 Madison Ave, New York, NY 10016, USA. 